\title{
Celestina: Documento bibliográfico (suplemento número 36)
}

\author{
Devid Paolini \\ The City College of New York
}

2336. BERNALDO DE QUIRÓS MATEO, José Antonio, «Fernando de Rojas y la calidad literaria del planto de Pleberio», Etiópicas 10 (2014), 128-150.

A través de un detenido análisis del planto de Pleberio, el autor defiende la postura de García-Valdecasas que veía en el monólogo del padre de Melibea un total desacierto. En particular, evidencia su mediocridad, un estilo totalmente deficiente y la presencia de un personaje muy mal desarrollado.

2337. CAMPOS GARCÍA ROJAS, Axayácatl, «Ecos de La Celestina en el Primaleón: objetos mágicos y prendas de amor», Celestinesca 37 (2013), 9-26.

Entre las tradiciones literarias que confluyeron en los libros de caballerías se encuentra también, sin duda alguna, LC. El estudio trata, en particular, de los elementos celestinescos que pueden rastrearse en el Primaleón (1512) y de cómo estos fueron recreados y reinterpretados en la novela de caballería.

2338. CANET, José Luis, "A vueltas con las ediciones de la Comedia de Calisto y Melibea», en Texto, edición y público lector en los albores de la imprenta, eds. M. Haro Cortés y J. L. Canet, Valencia: Universitat, 2014, 53-82.

Trabajo que complementa y amplía su precedente artículo titulado "Celestina 'sic et non': ¿Libro escolar-universitario?», Celestinesca 31.1 (2007), 23-58 y su edición crítica de la CCM (Valencia, Publicacions de la Universitat de València, 2011). El autor se centra en los talleres de impresión de las tres CCM conocidas y en las ediciones que se imprimieron allí entre 1500 y 1502; aporta datos para demostrar la posterioridad del impreso de Burgos con respecto al de Toledo; señala toda una serie de relaciones que unirían mercaderes, libreros (los hermanos 
Gorricio) y los poderes religiosos (en particular el Cardenal Cisneros) y monárquicos (los Reyes Católicos); y, por último, especula que estos mismos tuvieron un papel directo en la impresión de la CCM que nació como libro de texto con el propósito de presentar una nueva religiosidad y manera de educar a los jóvenes.

2339. CATOIRA, Loreto, "Valores semánticos de alahé en las traducciones inglesas de La Celestina», Lemir 16 (2012), 283-300.

El trabajo se centra en la expresión "alahé» que aparece siete veces en la obra maestra española. Intenta explicar su significado y muestra cómo se tradujo en diferentes traducciones inglesas de $L C$.

2340. CORFIS, Ivy A., "Readers and Comedy in Celestina», Celestinesca 37 (2013), 27-48.

Un estudio de la importancia que tuvo el público/lector en la continuación de Comedia a Tragicomedia. Las dos versiones pertenecerían al género cómico según el patrón de la comedia romana y humanística.

2341. DEAN SIMPSON, Dana, "Variances on courtly archetypes in $\mathrm{La}$ Celestina and Eréndira", Cuaderno internacional de estudios humanísticos 13 (2010), 9-14.

Se compara LC con Eréndira de Gabriel García Márquez y se estudia, en particular, la parodia del amor cortés en las dos obras.

2342. GARCÍA SOORMALLY, Mina, Magia, hechicería y brujería entre "La Celestina» y Cervantes. Sevilla: Renacimiento, 2011. 636 pp. ISBN 97884-8472-648-7.

El segundo capítulo («La encrucijada española: las artes celestinescas», págs. 203-394) está dedicado a $L C$. Tras un breve apartado que trata del género de la obra, se analiza la relación de la vieja alcahueta con la brujería y hechicería. También se centra en la celestinesca.

2343. GILES, Ryan, «El Triunfo de Átropos en la Celestina», Anales de historia del arte, núm. extra 1 (2012), 285-294.

El trabajo estudia la invocación a las tres hadas al final de $L C$ y su posible significado. Tras analizar el papel de estas figuras mitológicas según se desprende de las artes visuales de la época, se detiene, en particular, en la última de ellas, Átropos, y señala una posible influencia de los Triunfos de Petrarca en la obra maestra española. 
2344. GRACIA, Paloma, «Reescritura celestinesca de un episodio del $\mathrm{Ba}$ ladro del sabio Merlin: prostitución y libertad en el incunable publicado en Burgos, 1498", Revista de literatura medieval 25 (2013), 87-102.

El Baladro del sabio Merlín, impreso en Burgos en 1498, presenta un episodio muy celestinesco: el de la corrupción por parte de una «mala vieja» de una de las tías del profeta que acabará volviéndose una prostituta. Tras el cotejo del pasaje en cuestión del incunable burgalés, mucho más extenso, con el texto del ms. 1877 de la Biblioteca Universitaria de Salamanca y de la edición de Sevilla, 1538, la estudiosa señala los elementos que se han añadido y modificado. Por último, especula sobre la posible fuente de esta "reescritura celestinesca».

2345. HERAS GONZÁLEZ, Juan Pablo, "La Celestina como emblema del exilio republicano en México: la versión de Álvaro Custodio», Celestinesca 37 (2013), 49-86.

Un detenido análisis de las versiones teatrales de $L C$ al cuidado de Álvaro Custodio donde se aclaran las razones que le empujaron a empezar su trayectoria artística con la obra de Rojas y se señalan los aspectos más sobresalientes de sus adaptaciones.

2346. HEUSCH, Carlos, «La comida, :tema integral de La Celestina?», Estudios humanísticos. Filología 32 (2010), 65-79.

Se analiza el tema de la comida como elemento clave y estructurante de $L C$ que ayuda a entender el "mundo social» de la obra y su modernidad. La comida definiría la pertenencia de un personaje a uno u otro estamento social y la "mentalidad del hambre», así como la define el autor, representaría uno de los elementos fundamentales de la prepicaresca.

2347. ILLADES AGUIAR, Gustavo, «El carácter delictivo de los personajes celestinescos a la luz de las Siete Partidas", Celestinesca 37 (2013), $87-100$.

El autor estudia los diferentes crímenes que se cometen en $L C$ a la luz de las Siete Partidas. Se centra, en particular, en la dinámica tanática que muestra una clara conciencia jurídica sistémica. La causa principal de estas acciones delictivas sería la «desesperación» de los personajes.

2348. INIESTA, Ricardo, "Celestina o el teatro de la crueldad", ADE teatro: Revista de la Asociación de Directores de Escena de España 141 (2012), 132-137. 
El director de teatro Ricardo Iniesta comenta su última puesta en escena de $L C$ en 2012 recordando cómo y por qué decidió representar la obra maestra española. Asimismo habla de su adaptación, la ideología que se percibe, los cuatro puntos claves que decidió incluir en su dramaturgia (el dinero; la lucha de clases; la conciencia del tiempo y la importancia de los personajes femeninos), la escenografía, etc.

2349. MACÍAS DE YOON, Claudia, «Pedro Henríquez Ureña y su edición de La Celestina», Sincronía 64 (2013), 1-13.

Un análisis de la edición de LC que preparó Henríquez Ureña en 1938.

2350. MADRIGAL, José Luis, «De nombres y lugares: el corpus del licenciado Arce de Otálora», Lemir 18 (2014), 89-118.

El estudio de las recurrencias de expresiones particulares y bien definidas alrededor de nombres propios y topónimos permite atribuir a Arce de Otálora la autoría de un sermón jocoso compuesto en las Navidades de 1550. Hay más. También la Celestina comentada y, sobre todo, el Lazarillo de Tormes comparten la misma coincidencia verbal y el mismo empleo y cita de autoridades.

2351. MAGGI, Eugenio, "El halcón de Federico de Lope de Vega, una reinterpretación anticortés de Decamerón, v, 9", Anuario Lope de Vega. Texto, literatura, cultura XIX (2013), 67-93.

Se presenta una nueva lectura/interpretación de El halcón de Federico, comedia de Lope de Vega inspirada en la novella v, 9 del Decamerón. En su obra el dramaturgo habría deformado, desmitificado y desacralizado a sus personajes y símbolos en clave anticortés a través de un filtro celestinesco.

2352. PALMA VILLAVERDE, Mariel Aldonza, «El hilo del que está tejido el manto de Celestina», Celestinesca 37 (2013), 101-118.

Análisis del hilo discursivo que se construye alrededor de las unidades léxicas que se refieren al vestido. La vieja alcahueta solo estaría interesada en obtener un manto nuevo, prenda que representaría para ella un símbolo de estatus de la prosperidad de que la gozó en el pasado. Sin embargo, este deseo la llevará hacia la muerte.

2353. PAOLINI, Devid, "Celestina: Documento bibliográfico (suplemento número 35)», Celestinesca 37 (2013), 223-240. 
En el último suplemento bibliográfico se han agregado más de 70 entradas que desde 1985 suman ya 2335.

2354. PAOLINI, Devid, «Sobre una edición (des)conocida de La Celestina y viejos errores bibliográficos», Revista de literatura medieval xxv (2013), 303-305.

Una breve nota acerca de una edición de $L C$ impresa en Barcelona en 1566 de la que se habían perdido los rastros. También se corrige un error bibliográfico que procede de Simón Díaz y que todavía sigue repitiéndose en los estudios más recientes de la obra.

2355. PARDO DE SANTAYANA, Manuel, Antonio GARCÍA-VILLARACO, Mar REY BUENO y Ramón MORALES, "Naturaleza a través de la botánica y zoología en la literatura renacentista española: La Celestina», Asclepio: Revista de historia de la medicina y de la ciencia 63.1 (2011), 249-292.

Un estudio pormenorizado, tanto científico como lingüístico, de todas las referencias a plantas y animales que se encuentran a lo largo de $L C$. Se desprende que Celestina tenía unos grandes conocimientos del universo vegetal.

2356. PÉREZ ÁLVAREZ, David, "Sobre el Don Juan de Torrente Ballester: la juerga de un demonio en el burdel de Celestina», Variaciones de lo metarreal en la España de los siglos XX y XXI, coords. B. Greco y L. Pache Carballo. Madrid: Biblioteca Nueva, 2014, 117-126.

El trabajo se centra en el capítulo II del Don Juan de Gonzalo Torrente Ballester y analiza, en particular, el episodio del demonio Garbanzo Negro, que se ha apoderado del cuerpo de un fraile, en el burdel de la vieja alcahueta Celestina.

2357. PÉREZ GONZÁLEZ, Rosalía, “¿Cómo rezan los personajes de La Celestina?», Lemir 17 (2013), 179-192.

Se detiene en la religiosidad de los personajes de $L C$ poniendo en evidencia parte de su compleja psicología y la heterodoxia y amoralidad de sus rezos.

2358. RAMÍREZ SANTACRUZ, Francisco, «El aspecto paremiológico en el Retrato de la Lozana Andaluza de Francisco Delicado», Estudios humanísticos. Filología 31 (2009), 271-302. 
El artículo se centra en el estudio de los proverbios en la Lozana andaluza y muestra cómo algunos de estos, siguiendo una técnica que viene de $L C$, se manipulan a nivel lexical y morfológico, o en el significado, con el objetivo de cambiar y transgredir su moraleja. De esta manera la obra de Francisco Delicado representaría un eslabón fundamental entre la Tragicomedia y el Lazarillo, el Guzmán de Alfarache y el Quijote.

2359. RINCÓN GONZÁLEZ, María Dolores, «El término tragicomedia en el drama humanístico", De ayer a hoy: influencias clásicas en la literatura, coords. A. López López, A. Pociña Pérez y M. de Fátima de Sousa e Silva. Coimbra: Centro de Estudos Clássicos e Humanísticos da Universidade de Coimbra, 2012, 441-447.

Se analizan las prefaciones de los dramas humanísticos de Carlo Verardi con el fin de contestar a algunas de las preguntas teóricas que tuvieron los humanistas acerca del teatro antiguo y renacentista. El término «tragicomedia» le habría llegado a Rojas de las obras de Verardi.

2360. RODRÍGUEZ PUÉRTOLAS, Julio, «Fernando de Rojas y su Celestina», República de las Letras: revista literaria de la Asociación Colegial de Escritores 122 (2011), 7-14.

Se centra en la visión negativa, pesimista y catastrófica del mundo que se desprende de diferentes pasajes de la obra.

2361. ROMERO DEL CASTILLO, María Pilar, «El léxico de los afeites en el Corbacho y La Celestina", Tonos digital: Revista electrónica de estudios filológicos 26 (2014), s. pág.

Un estudio comparativo del léxico dedicado a los afeites en el Corbacho y LC.

2362. SAGUAR GARCÍA, Amaranta, «Las premisas bíblicas de un silogismo falaz: Celestina y Eclesiático 13", El eterno presente de la literatura: Estudios literarios de la Edad Media al siglo XIX, eds. M. T. Navarrete Navarrete y M. Soler Gallo. Roma: Aracne Editrice, 2013, 85-94.

Análisis del discurso con el que Celestina, casi al final del acto I, intenta convencer a Pármeno para que se alíe con ella y Sempronio. En particular se estudian las referencias que provienen de Eclesiástico 13 y se muestra cómo la vieja alcahueta construye un silogismo totalmente falso que, por supuesto, le sirve para sus propósitos. 
2363. SAGUAR GARCÍA, Amaranta, «La recepción de Celestina como objeto de meditación", De lo sobrenatural a lo fantástico: Siglos XIII-XIX, coord. B. Greco y L. Pache Carballo. Madrid: Biblioteca Nueva, 2014, 89-100.

Tanto en el acróstico como en las coplas finales se sugiere una lectura privada, silenciosa y meditativa de $L C$. Todo esto reforzaría el fin didáctico-moral de la obra que fue luego cuestionado por la evolución del moralismo y el cambio de ideología acerca de la utilidad de exponer al mal con el objetivo de acercar al bien.

2364. SANMATEU, Xelo, "La puesta en escena de la Edad Media en el cine: La Celestina de César Fernández Ardavín", L’Edat Mitjana en el cinema i en la novel-la histórica, eds. J. Ll. Martos y M. Garcia Sempere. Alacant: Institut Interuniversitari de Filologia Valenciana, 2009, 535-553.

Se estudia la versión cinematográfica de $L C$ de Fernández Ardavín (1969) como contrapunto a la película El Cid de Anthony Mann (1961). Las dos adaptaciones serían antagónicas por recursos (escasos los de la primera, enormes los de la segunda) y utilización del medio fílmico (artístico, teatral y visual el primero, verosímil y realista el segundo). Se presenta al final un paralelo con la película Henry $V$ de Laurence Olivier (1944) que tantos rasgos comparte con la de Fernández Ardavín.

2365. SCHMIDHUBER DE LA MORA, Guillermo, "La estirpe de las siete Celestinas: de Fernando de Rojas a Sor Juana Inés de la Cruz», Sincronía 14.51 (Summer 2009), s. pág.

Un breve recorrido que desde la primera aparición de $L C$ nos lleva hasta Sor Juana Inés de la Cruz, coautora/continuadora de La gran comedia de la segunda Celestina que Agustín de Salazar y Torres dejó incompleta a su muerte.

2366. SNOW, Joseph T., "Confederación e ironía: crónica de una muerte anunciada, Celestina, autos I-XII», Celestinesca 37 (2013), 119-138.

Artículo que intenta explicar el porqué de la muerte de la vieja alcahueta y el papel que ella misma tuvo en su destino. La elección de juntarse con Pármeno y Sempronio llevará a todos los miembros de esta confederación a un mismo «amargo y desastrado fin».

2367. SNOW, Joseph T., "Historia crítica de la recepción de Celestina 1499-1822. Entrega IV», Celestinesca 37 (2013), 151-204. 
Cuarta entrega de este catálogo que reúne referencias a $L C$ o a sus personajes de 1515 a 1816. Las primeras tres se publicaron, respectivamente, en: Celestinesca 21 (1997), 115-172; Celestinesca 25 (2001), 199-282 y Celestinesca 26 (2002), 53-121.

2368. TORREGROSA DÍAZ, José Antonio, "CCuando andan a pares los diez mandamientos' (Celestina, IX). Interpretación", Celestinesca 37 (2013), 139-148.

En el artículo se intenta explicar el sentido de la frase "Cuando andan a pares los diez mandamientos" que enuncia Elicia en el acto noveno. Esta particular expresión solo se encuentra documentada en $L C$ e indicaría algo imposible de realizar.

2369. VILLAGRÁ TERÁN, María Montserrat, «La Lozana andaluza» en el siglo de los Humanistas: un "retrato» que parodia otro retrato, UNED, Tesis Doctoral, 2012-2013. Dir: M. Á. Pérez Priego.

Un estudio detenido de La Lozana andaluza. En diferentes apartados se hace referencia a $L C$ y la celestinesca.

2370. VILLEGAS, Simón Andrés, «Exempla: la función didáctica en el Libro de Buen Amor y La Celestina», Lingüística y Literatura 63 (2013), 319-326.

Estudio que subraya la importancia de los exempla y el didacticismo en el Libro de buen amor y LC. 